\title{
Quasi-Non-destructive Characterization of Carburized Case Depth by an Application of Centerless X-ray Diffractometers
}

\author{
Mate Sepsi, Peter Szobota, and Valeria Mertinger
}

\author{
Submitted: 30 June 2021 / Revised: 6 September 2021 / Accepted: 5 January 2022 / Published online: 7 February 2022
}

\begin{abstract}
A new application of a centerless $x$-ray diffractometer was proposed that goes beyond residual stress measurements during the regular operation of such equipment. During depth residual stress measurement, it is possible to fit the measured interference function of the ferrite (211) with a different number of curves as a function of depth. The different curves corresponded with the appearance of ferrite fractions with different grain sizes and concentrations in ferrite, perlite, bainite, or martensite. Accordingly, different microstructures were non-destructively detected through the thickness of the carburized layer, and a good correlation was found with results from metallography and hardness testing. This novel method was validated on solid and gas carburized samples, but more work is needed to apply it to other microstructures.
\end{abstract}

Keywords case depth, carburized layer microstructure, hardness, non-destructive characterization, portable XRD, residual stress measurement, $\mathrm{x}$-ray diffractometer

\section{Introduction}

Carburizing is a case-hardening process in which carbon is diffused into a thin steel surface layer at elevated temperatures, while the steel is typically austenitic. Carburizing is usually followed by a quenching and tempering process to produce tempered martensite at the surface (case depth), under which there is a more ductile bainitic core. The carbon gradient from carburizing creates a gradient in the steel surface hardness, strength, and wear resistance of the component. Hosford (Ref 1) and Réti (Ref 2) have shown that the main advantage of carburizing is that it also produces compressive residual stress on the surface of the component. Service life, especially wear and fatigue resistance, can be significantly improved by the well-controlled residual surface stress state of various components. Wang et al. (Ref 3) showed that the amount of carburizing-induced residual stress on a wind turbine gear leads to a bilinear curve in the gear's contact fatigue life. As the magnitude of the tensile residual stress increases, the rolling contact fatigue life decreases linearly.

In contrast, once the magnitude of the compressive residual stress exceeds a specific value, the contact fatigue life does not increase anymore. Wu et al. (Ref 4) highlighted the advantage of shot peening coverage on the carburized rollers. Not only the residual stress was improved, but the retained austenite was

Mate Sepsi, Peter Szobota, and Valeria Mertinger, University of Miskolc, Miskolc-Egyetemváros H3515, Hungary. Contact e-mails: femsepsi@uni-miskolc.hu and femvali@uni-miskolc.hu. also transformed on the carburized layer after shot peening. Sugimoto et al. (Ref 5) applied severe plastic deformation to increase the compressive residual stress on a vacuum carburized steel.

Residual stress control often involves technology design supported by finite element simulation, as Hiremath et al. (Ref 6) and Li et al. (Ref 7) did on various carburized steel specimens and gears, respectively. O'Brien and Yeddu (Ref 8) used macroscale simulation and gained opposite results to $\mathrm{Wu}$ et al. (Ref 4) about the retained austenite. They showed that a carburized case with a high retained austenite volume fraction gives better fatigue than those with low retained austenite. Improper residual stress conditions can cause a variety of problems. Jo et al. (Ref 9) have shown that carburized steel exhibited cycling softening under both axial and torsional loading, while Freborg et al. (Ref 10) and Tewary et al. (Ref 11) focused on the distortion mechanisms and structural instability. Shoji et al. (Ref 12) pointed out that the heterogeneity in material chemistry and microstructure influences stress corrosion cracking. It can be concluded the efficiency of the carburizing process in terms of the lifetime of the component is mainly determined by the residual stress state. Despite this, the evaluation of carburizing process on a steel surface is traditionally accomplished by metallography and hardness measurements since the technology was introduced to the industrial practice in the last decades of the nineteenth century. The advantage of these methods is that carried out easily and cost-effectively in an industrial environment, and they are standardized and accepted. On the other hand, these are destructive methods (Ref 13).

However, a variety of non-destructive testing approaches have been investigated. One such technique was applied by Gogolinskii et al. (Ref 14), where portable hardness testing was used for surface characterization. Still, they concluded that this method does not meet the standards for the conventional hardness scale. Rodrigues et al. (Ref 15) successfully applied an ultrasonic test associated with signal processing and 
machine learning technique as a novel procedure for estimating the level of carburizing. Mercier et al. (Ref 16) proposed eddy current testing to characterize the extent of decarburization. They concluded that the eddy current technique is susceptible to surface modification, but it needs reference samples for industrial control. Amiri et al. (Ref 17) used an impedance plane for presenting results in eddy current testing for the determination of surface carbon content after carburizing.

One type of non-destructive, increasingly common device in industrial practice and on-site measurements is portable, centerless X-ray diffractometers (XRD) developed for residual stress testing. According to Mueller (Ref 18) the trend of the increasing demand is present in the automotive industry. Dive and Lakade (Ref 19) explained this need for residual stress measurement and presented the industrial usage of the portable residual stress measuring XRD systems among the other non-destructive methods. In Whitley's thesis (Ref 20) one can read about the portable residual stress measuring XRD systems utilization on military and marine fields from the 1980s and how these instruments helped to understand the structural failures of the different welded materials. The test principle is that the residual stress can be calculated from a change in the distance of a series of planes (hkl). Accordingly, the interference function of an (hkl) series is detected, and the Bragg angle is determined. By using these devices, of course, the residual stress state after cementation can also be characterized, a semidestructive way like Filip et al. (Ref 21) did. Our proposal is to determine not only the value of the residual stress but also all the information that can be obtained from a diffraction signal. In the present case, this is the full width at half maximum (FWHM) parameter and the correlated carbon gradient and the resulting change in microstructure.

Centerless diffractometers have not yet been used to characterize the surface carbon content. However, the measured parameter signal shows a much stronger correlation with the carbon content than previously mentioned methods. In the literature, one can find several examples for using conventional diffractometers to determine the carbon content or its change in the different phases or microstructure features based on the interference peaks radial distribution. Ortiz et al. (Ref 22) studied the crystalline quality and carbon content in carbon steels with the help of infrared photocarrier radiometry. They analyzed the FWHM values of XRD measurements data. In another study, Lara et al. (Ref 23) presented a similar study complemented by thermal characterization. Garcia et al. (Ref 24) investigated the carbon content of retained austenite in bainitic steel by atom probe tomography and XRD, and they found a good match in the results. Luo (Ref 25) showed a Gaussian peak fitting method for XRD diffraction peaks and how to separately measure the volume fraction and tetragonal ratio of co-existing lath and plate martensite in ultra-highstrength steels. This method was applied to investigate the decarburization of martensite during a tempering treatment.

These portable diffractometers, due to their centerless arrangement, allow operation without destroying or altering the specimen. During our practical experience, Sepsi et al. (Ref 26) and Sepsi et al. (Ref 27) showed that with XRD on shafts and gears, the negative (disturbing) effect of decarburization (carbon loss on the surface) could be detected during residual stress measurement. Szobota et al. (Ref 28) showed that decarburization could cause a change not only in the stress state but also in the FWHM of the interference function of the ferrite (211) during residual stress measurement. Several authors report FWHM data with residual stress measurements. Suominen et al. (Ref 29) presented a study on high-strength steel weld toes and fatigue life. They found that relatively higher FWHM values indicate a hardened surface. Using shot peening, $\mathrm{Fu}$ et al. (Ref 30) showed a connection between hardness, residual stress, and microstructure. They also identified a linear relationship between the FWHM and hardness values. Similar results can be obtained after ultrasonic shot peening, according to Li et al. (Ref 31). Kelleher et al. (Ref 32) studied the effect of the roller straightening process in railway rails and worn exservice rails. During their XRD measurements, they found a correlation between FWHM values and residual stresses. Dias et al. (Ref 33) investigated hot-rolled 42CrMo4 steels and their residual stress state after various heat treatments. They compared their XRD and Barkhausen noise measurement results and examined how the microstructure features influenced them.

The shape and the parameters of the ferrite interference function (FWHM) are influenced by several physical factors such as the amount of carbon in solid solution, lattice distortion, and crystallite size. These parameters can be precisely determined by analysis of the complete diffraction profile with a conventional XRD, such as a Rietveld analysis, as shown by Young (Ref 34). Centerless X-ray diffractometers, as they have been developed explicitly for residual stress testing, are suitable for recording only one or two interference functions in the large Bragg angle range. This means that a full-profile analysis cannot be performed, but the measured interference functions (one or two) data can be determined with high accuracy. This observation gave us the idea to use the diffractometer not only to show the residual stress but to find the depth where, in addition to martensite, other microstructure elements such as bainite, perlite, or ferrite also can form because of the lower carbon concentration. The carbon content in ferrite and other allotropic iron phases (especially its crystallite size) are very different in these microstructural elements. In the case of a mixed microstructure, the measured interference function of ferrite appears as a superposition of signals of a multi-component structure.

This work proposes a novel, non-destructive procedure for identifying different carburization levels and the case depth. Signal deconvolution of the interferential function during residual stress measurement was compared with the results of conventional destructive methods such as metallographic studies and hardness testing.

\section{Material and Experimental Procedures}

The hot-rolled C45 grade steel bar specimen used for the experiments is shown in Fig. 1. This low-alloyed and tough structural steel with medium strength is frequently used in the automotive industry. The carburized layer was produced in an electric resistance furnace in an industrial environment, together with other industrial components. Surface-hardened layers were produced by two carburizing methods: the pack method for 20 hours or gas carburizing for 14 hours. In the case of gas carburizing, 1.2 carbon potential was used. Both carburizing processes were carried out at $920^{\circ} \mathrm{C}$, and subsequent air cooling was applied.

After carburizing, the samples were cut (Fig. 2), and half of them received an additional hardening heat treatment with 


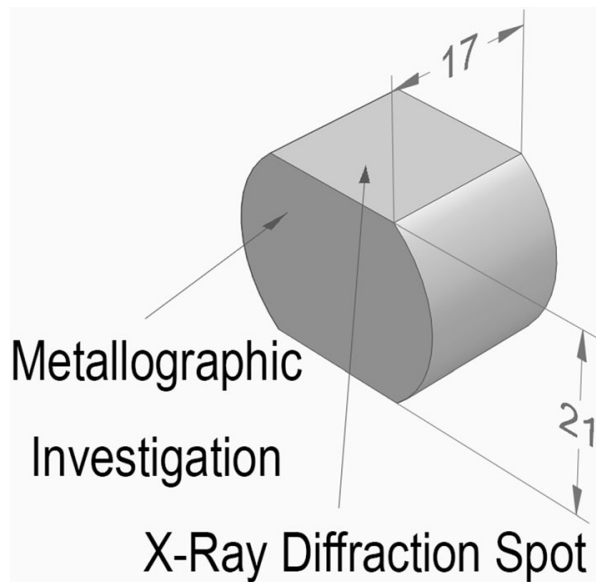

Fig. 1. Geometry of experimental specimens subjected to carburizing

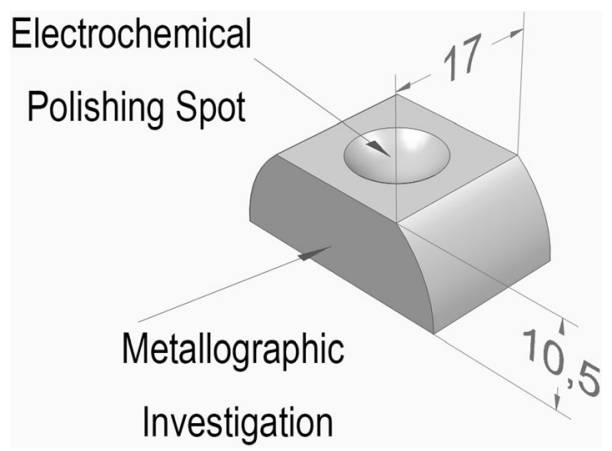

Fig. 2. Geometry of experimental specimen after cutting, surfaces investigated during metallographic and x-ray diffraction (electrochemical polishing spot), in $\mathrm{mm}$

austenitization at $900^{\circ} \mathrm{C}$ for 30 minutes and subsequent oil quenching. A chemical surface cleaning process was used to remove the thin oxide layer. Figure 2 also shows the investigated surfaces during metallographic examination and XRD test values as a function of depth (electrochemical polishing spot).

Optical microscopic composite images were prepared using a Zeiss Axio Imager optical microscope. Image analysis was used to determine the martensite volume fraction based on Cprob software by Póliska et al. (Ref 35). It was carried out with a 45 -pixel wide $(8.25 \mu \mathrm{m})$ sliding window, and a threeperiod moving average was applied as smoothing. Hardness measurements were taken using an Instron Tukon 2100B (Wilson Instruments) microhardness tester with a load of $100 \mathrm{~g}$. The dwell time was 10 seconds. The first measuring point was at $20 \mu \mathrm{m}$ from the edge of the sample and then at $100 \mu \mathrm{m}$ increments toward the piece's core up to $3 \mathrm{~mm}$. Macrohardness was also performed with the load of $1000 \mathrm{~g}$ with $300-\mu \mathrm{m}$ increments, and the first point was at $200 \mu \mathrm{m}$ from the edge of the sample. The dwell time was 10 seconds. For each specimen, the measurements were taken in 4 parallel lines from the edge to the core. During the evaluations, the average values with the error bars are presented.

All four specimens were subjected to XRD measurements, where residual stress and interferential function parameters were detected through the depth. The depth measurements were

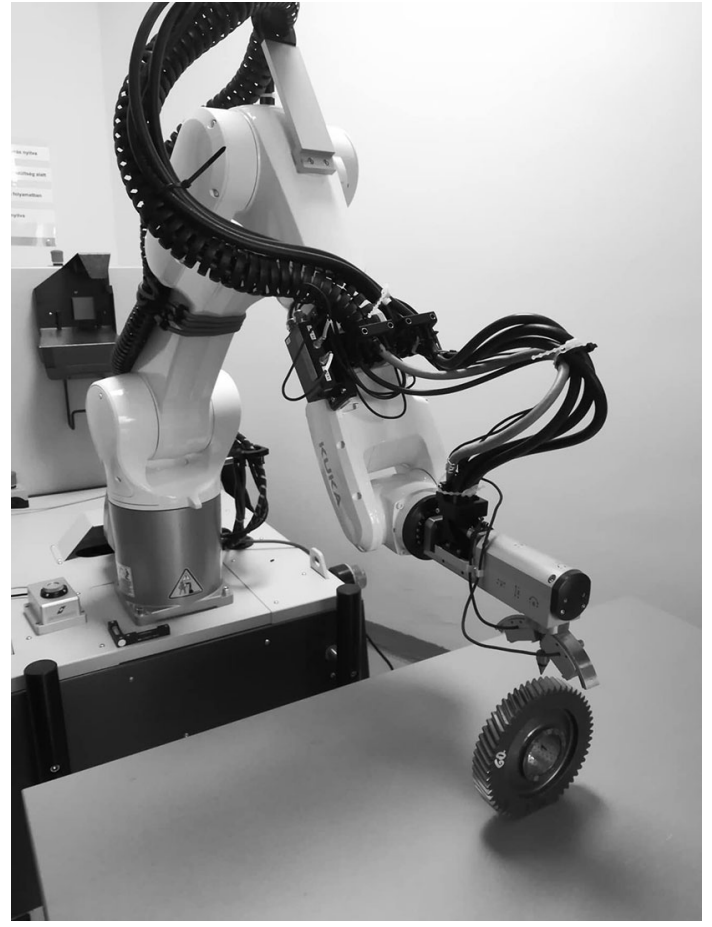

Fig. 3. Residual stress measurement with a Stresstech Xstress Robot centerless diffractometer

taken with electrochemical polishing (Struers MoviPol-5 machine). The first measurement point for all samples was made on the surface and then with $100-\mu \mathrm{m}$ increments toward the core of the sample, up to a depth of $3 \mathrm{~mm}$. The residual stress measurements were taken with a Stresstech Xstress Robot centerless x-ray diffractometer (Fig. 3), and the data were evaluated using the $\sin ^{2}$ PSI method, as discussed by Krawitz (Ref 36). Table 1 summarizes the parameters used during the XRD residual stress measurement and calculation. The FWHM data are recorded as an average of the FWHM (without deconvolution) data of the 16 signals determined at eight different tilt angles at a given depth. Additional analysis with parabolic background extraction and Gaussian peak deconvolution of the ferrite (211) interferential function was used to prove the presence of fractions of different crystallite sizes, i.e., different microstructures. The volume fraction of martensite was determined from the deconvolution of the diffraction signal. After peak deconvolution, the martensite fraction is given by the ratio between the area of the peaks with higher and lower FWHM values.

\section{Results}

\subsection{Light Microscopy}

Light microscopy mosaic and selective area images of cross sections of air-cooled and quenched samples are shown in Fig. 4 and 5, respectively. The region close to the surface of the air-cooled samples is purely perlite, and the ferrite appears at a lower depth. The longer carburizing time and higher carbon potential of pack carburization resulted in more increased carburized layer thickness. At a given depth, the perlite ratio (the carbon concentration) is always higher for the 20-hour 
Table 1 Parameters for the $x$-ray residual stress measurement

\begin{tabular}{llll}
\hline X-ray tube type & \multicolumn{1}{c}{ Cr } & \multicolumn{1}{c}{ Detector } & Two position sensitive \\
\hline Detector arm & $75 \mathrm{~mm}$ & Collimator & $\varnothing 2 \mathrm{~mm}$ \\
Tilt & $4 / 4,+45^{\circ} \ldots-45$ & Miller indices & $\mathrm{Fe}-(211)$ \\
Exposure time & $13 \mathrm{~s}$ & Poisson's ratio & 0.3 \\
Detector config. & modified PSI & Young's modulus & $211 \mathrm{GPa}$ \\
\hline
\end{tabular}
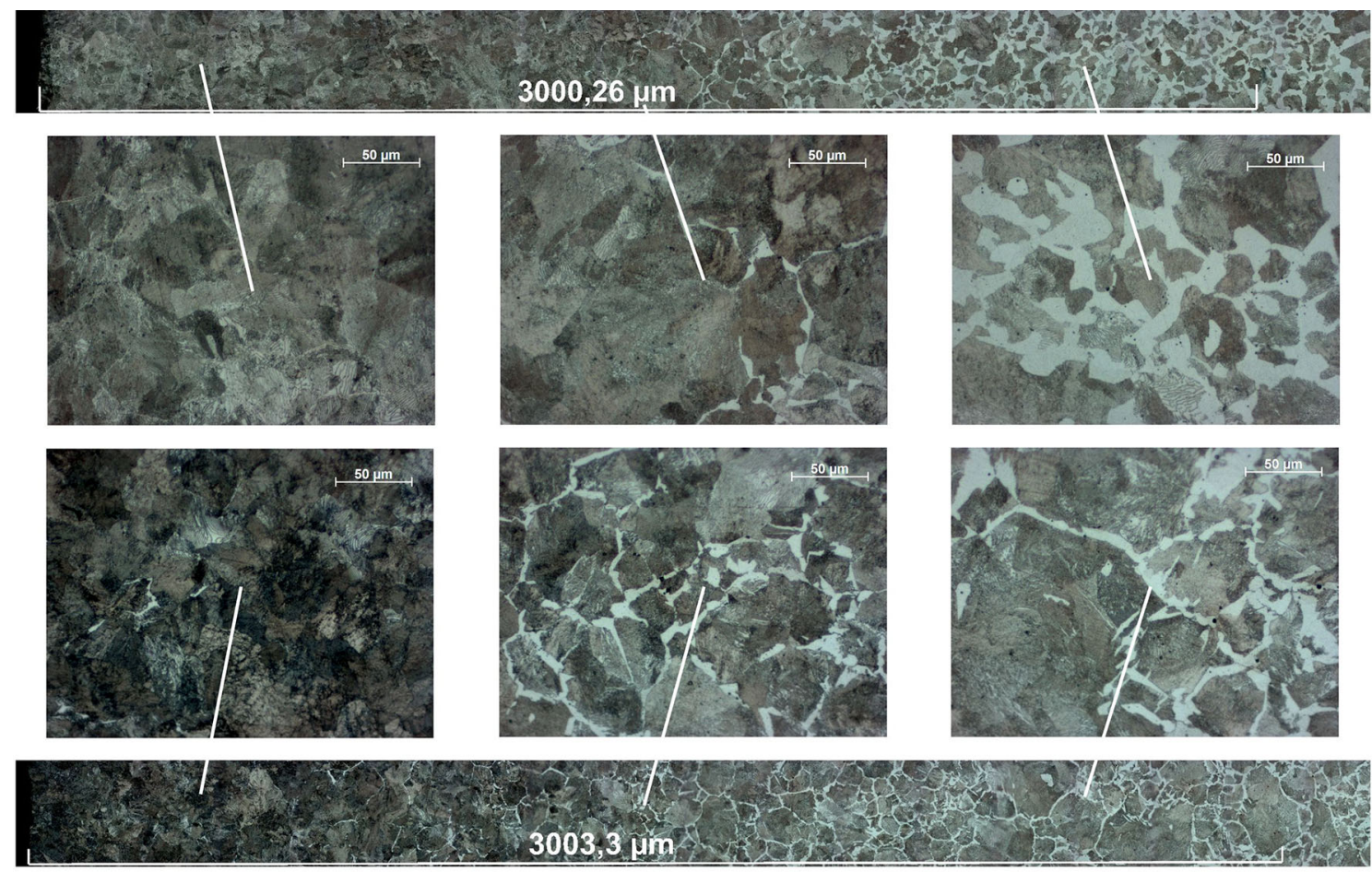

Fig. 4. Light microscopic mosaic and selected area images of cross section of the air-cooled 20-hour pack carburized sample (top) and gas carburized sample (bottom)

pack carburized sample. The microstructure shows a corresponding difference in the two types of carburized samples even after hardening. Regions close to the surface of the pack carburized samples are purely martensitic, while in the case of the gas carburized sample, perlite also appears. The amount of perlite increases significantly toward the core of the samples, and even bainite appears along the grain boundaries. A mixture of perlite, bainite, and martensite also can be detected at 3000 $\mu \mathrm{m}$ depth of both types of samples. The amount of softer microstructure elements (ferrite, perlite, bainite) other than martensite is higher at the same depth for the 14-hour gas carburized piece. Martensite volume fraction was determined on the quenched samples by Cprob image analysis software (Ref 35) on the presented mosaic images. Image analysis confirms the light microscope observations (Fig. 6). The martensite content of the pack carburized sample falls below $95 \%$ at a depth of $1000 \mu \mathrm{m}$ and then steadily decreases after that. The martensite volume fraction does not even reach $90 \%$ in the near-surface layers of the gas cemented sample. At a depth of $700 \mu \mathrm{m}$, a significant decrease starts. It is incorrect to assume a direct correlation between hardness and martensite fraction. The light microscopic examination shows that both samples' microstructural features and their proportions besides martensite are very variable.

\subsection{Hardness}

The microhardness data show a substantial error margin (Fig. 7), which the complex and inhomogeneous microstructure distribution can explain. Therefore, we also performed a macrohardness test (Fig. 7). From the results of the two measurements, it can be concluded that the hardness shows a decreasing tendency, and at a given depth, the hardness value is always higher for the 20-hour pack carburized sample. The carburization process took place in two stages. First was carburization, followed by air cooling, and the second was reheating half of the samples in a standard air furnace and subsequent quenching. During 30 minutes of reheating, decarburization (surface carbon burnout) in the furnace air atmosphere was inevitable. This causes a lower microhardness value near the surface.

\subsection{Residual Stress and FWHM results}

Figure 8 and 9 show the residual stress and FWHM values of carburized and quenched samples as a function of depth. The 

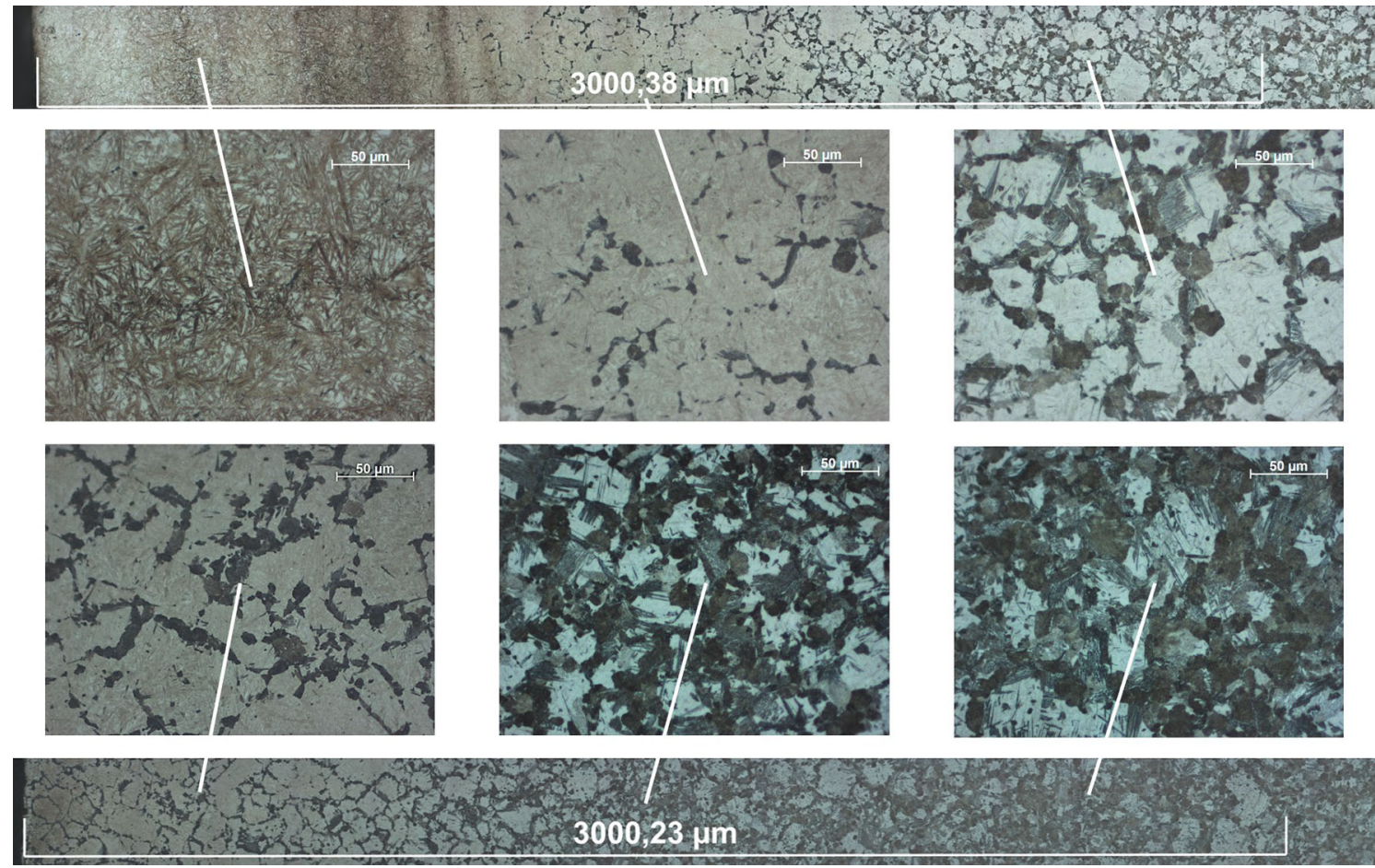

Fig. 5. Light microscopic mosaic and selected area images of cross section of the quenched 20-hour pack carburized sample (top) and gas carburized sample (bottom)

first result to be highlighted is that the gas carburizing resulted in much more consistent stress distribution. The low tensile stress of the surface layers formed because of the oxidation and decarburization during the hardening heat treatments and the oxide removal process. A low tensile or stress-free state can be observed at a depth of 100-200 $\mu \mathrm{m}$, which changes to compressive stress in the deeper regions. In pack carburizing, a plateau is formed, with values between -200 and $-300 \mathrm{MPa}$. While in the case of the gas carburized sample, after reaching the maximum compressive stress of $-200 \mathrm{MPa}$ there is a monotonic change in the tensile stress direction, and no plateau is observed at all. For the pack carburized sample, the plateau is up to a depth of 1500-1800 $\mu \mathrm{m}$, and then an increase in the tensile stress direction starts. The stress-free state is formed at a depth of $2300 \mu \mathrm{m}$ for the pack carburized sample and $1200 \mu \mathrm{m}$ for the gas carburized.

The effect of carburizing on the FWHM resulted in a maximum run-down curve. The maximum character, on the other hand, differs strongly for the samples carburized in different ways. In the pack carburizing sample, it is a characteristic maximum in a wide range. A small and narrow maximum characterizes the gas carburized sample. The maximum FWHM broadening is at $7^{\circ}$ and $3^{\circ}$ for the pack and gas carburized sample, respectively.

Figure 10 and 11 show the residual stress and FWHM values as a function of depth of as-carburized and air-cooled samples. Unlike hardened samples, air-cooled ones show no trend in either the average of FWHM or residual stress results. The residual stress values remain around $0 \mathrm{MPa}$ with a standard deviation of $\pm 50 \mathrm{MPa}$. The FWHM data cluster around a value of about $1.6^{\circ}$ with a standard deviation of $\pm 0.1^{\circ}$. The aircooled samples were investigated because of the signaldeconvolution problem. The Bragg angle shift is generally determined from the Gaussian fit of the measured interference function, and the residual stress value is calculated from this shift. In some cases, the interference functions obtained during XRD measurements in the "raw" state do not accurately fit the Gaussian curve, so the fit was performed manually. Figure 12 and 13 show an example where 2-peak deconvolution provides a better solution.

In Fig. 12 the solid gray line is the measured curve, and the A curve is the fitting curve after parabolic background extraction, while the dashed line is the composite function of A fitting function and the background. The fitting is imperfect in this case. Figure 13 shows a better solution for the fitting. In this case, an additional B curve was applied. The solid gray curve is the measured curve, and the dashed curve overlaps it, so fitting is perfect. The dashed line is the composite function of the A and the B curve and the background. The perfect fit shows that the measured curve consists of these two curves, meaning the ferrite phase is composed of two types of crystallites characterized by the A and the B curve.

The FWHM data of the two curves are typically different: curve B is much broader, suggesting martensite with a higher carbon concentration. To demonstrate that the curves are obtained by peak deconvolution corresponding to ferrites of different crystallite sizes, the analysis mentioned above was also performed on the air-cooled pack carburized sample containing ferrite and perlite (Fig. 14). Because of the small value of the FWHM data, the K $\alpha 2$ peaks ( $\mathrm{C}$ curves) must be considered. At the $500 \mu \mathrm{m}$ depth (Fig. 14), the dashed line composite curve $(\mathrm{A}+\mathrm{C}+$ background) fits well with the solid gray curve (measured data), but at $2000 \mu \mathrm{m}$ depth (Fig. 15) it does not, and an additional curve (B) is needed for a better fit (Fig. 16). The residual stress data were calculated from the data represented by the dashed line in each case.

Signal deconvolution thus means that the measured signal was fitted with two or three curves, and the parameters of the 

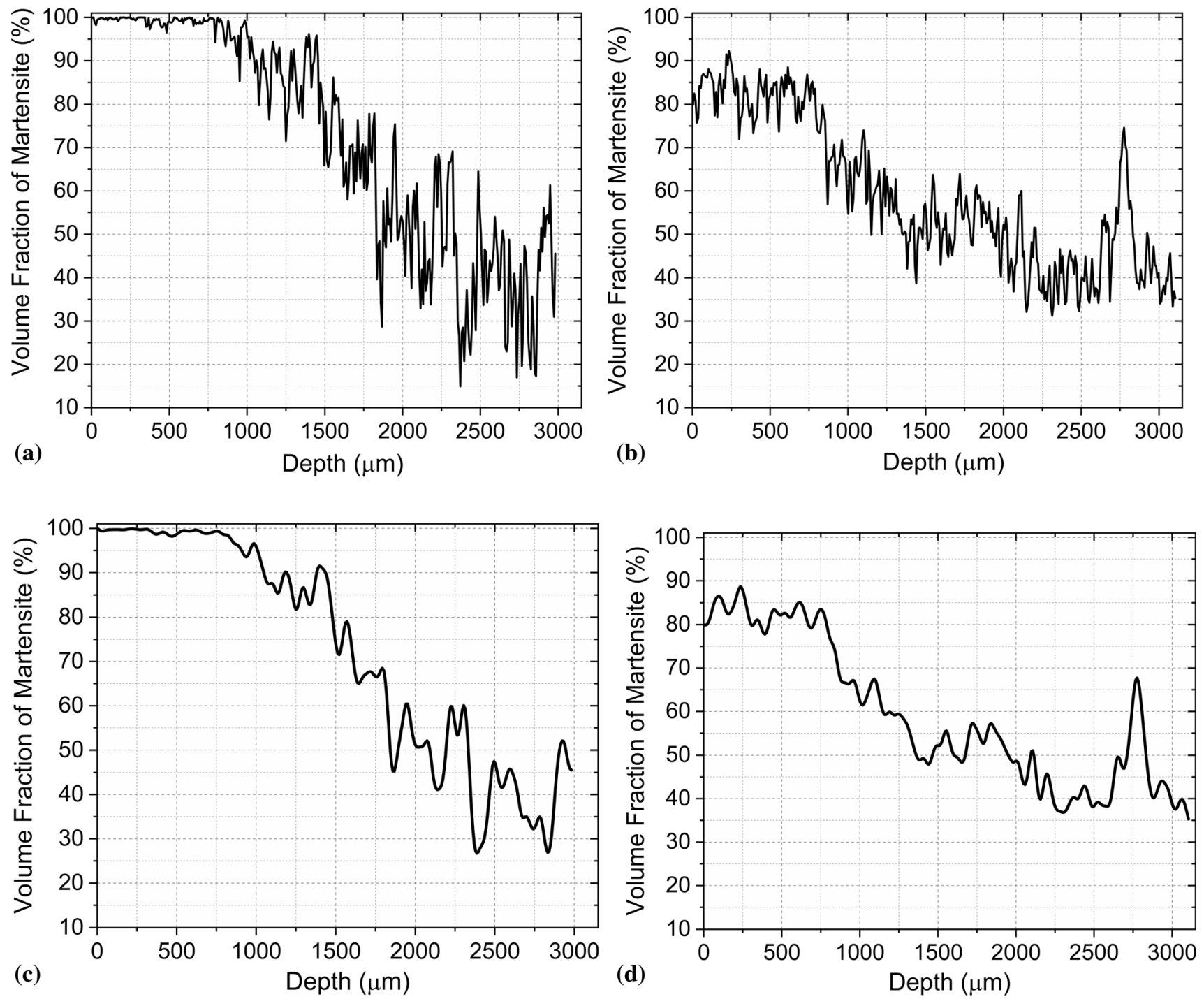

Fig. 6. The volume fraction of the martensite phase in depth is determined image analysis. (a) 20-hour pack carburized sample; (b) 14-hour gas carburized sample; (c) 20-hour pack carburized sample's result moving average smoothed; d) 14-hour gas carburized sample's result moving average smoothed
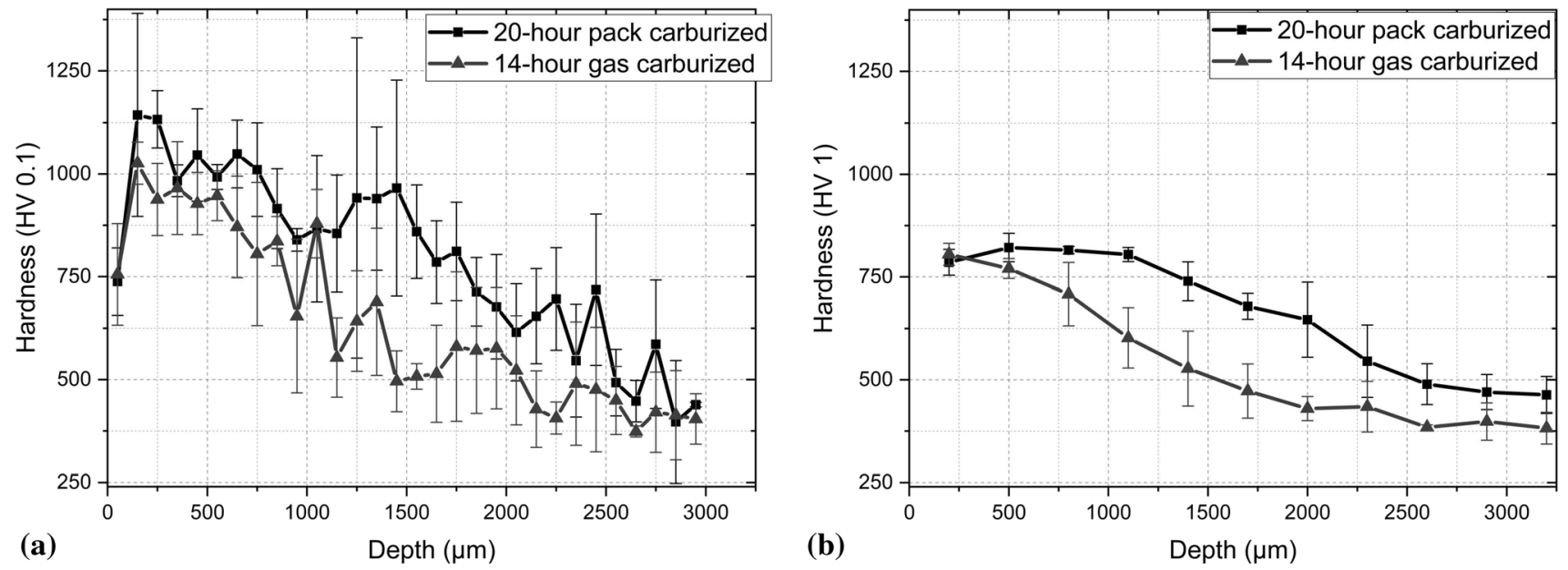

Fig. 7. (a) HV0.1 microhardness and (b) HV1 macrohardness results of the quenched samples as a function of depth. 


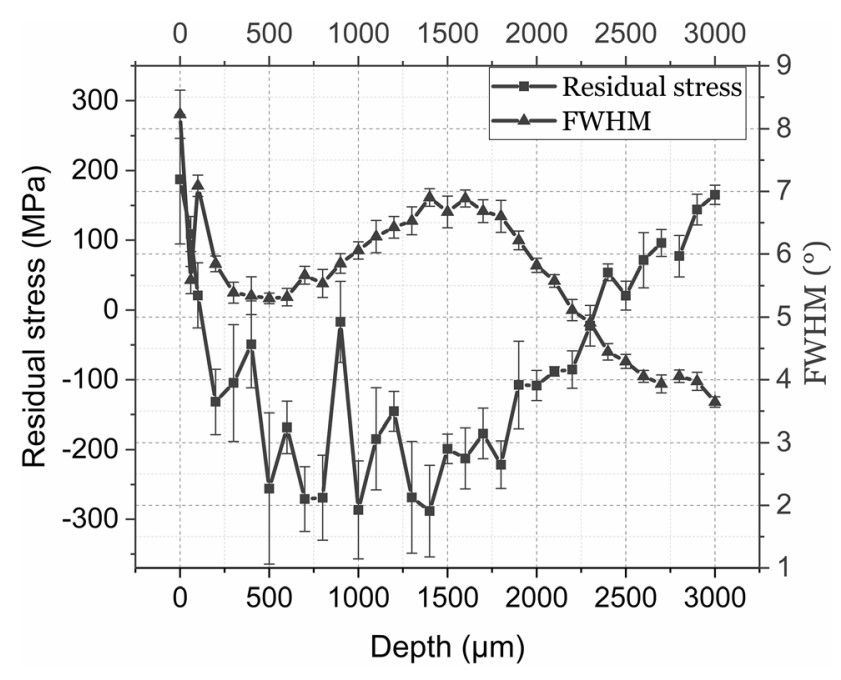

Fig. 8. Residual stress and FWHM data of 20-hour pack carburized and quenched sample

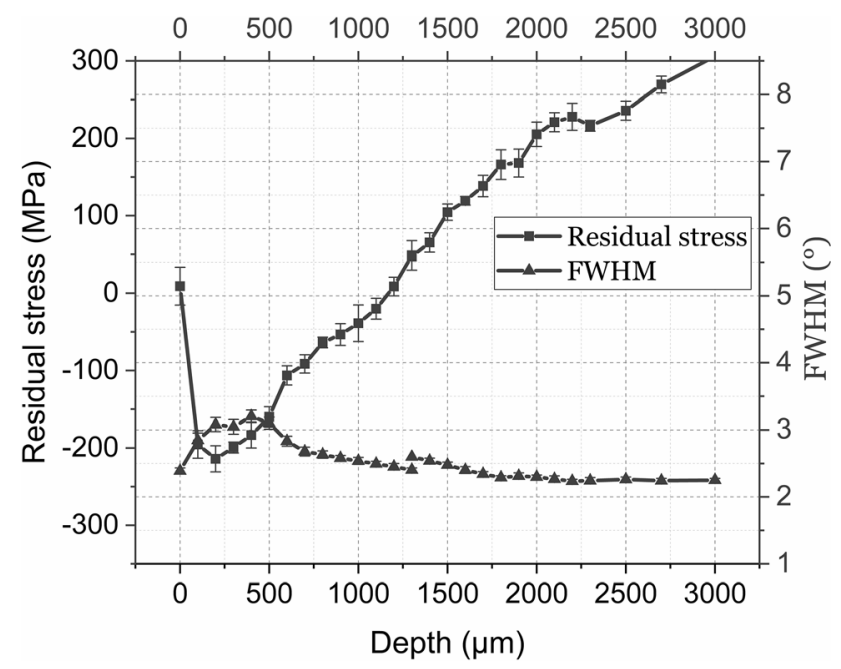

Fig. 9. Residual stress and FWHM data of 14-h gas carburized and quenched sample

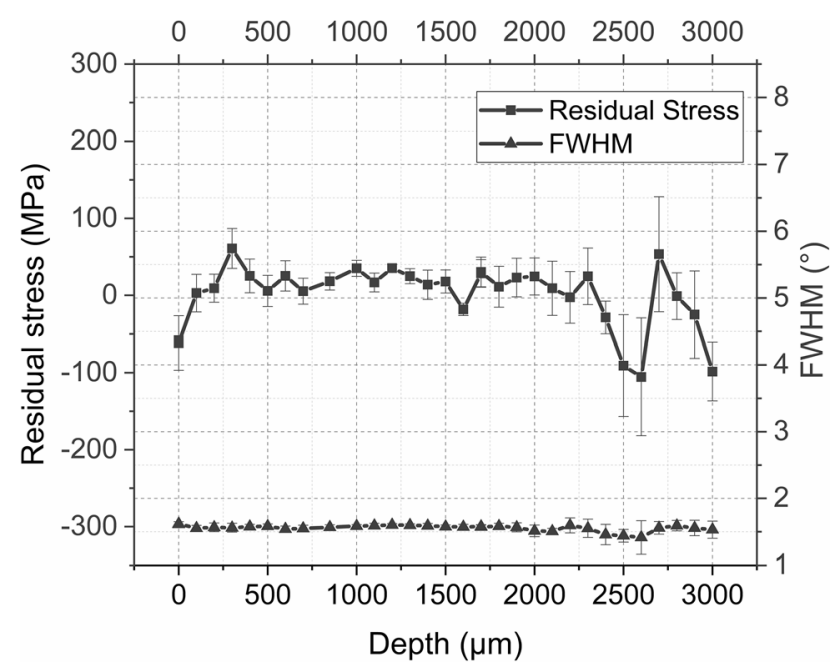

Fig. 10. Residual stress and FWHM data of 20-hour pack carburized air-cooled sample

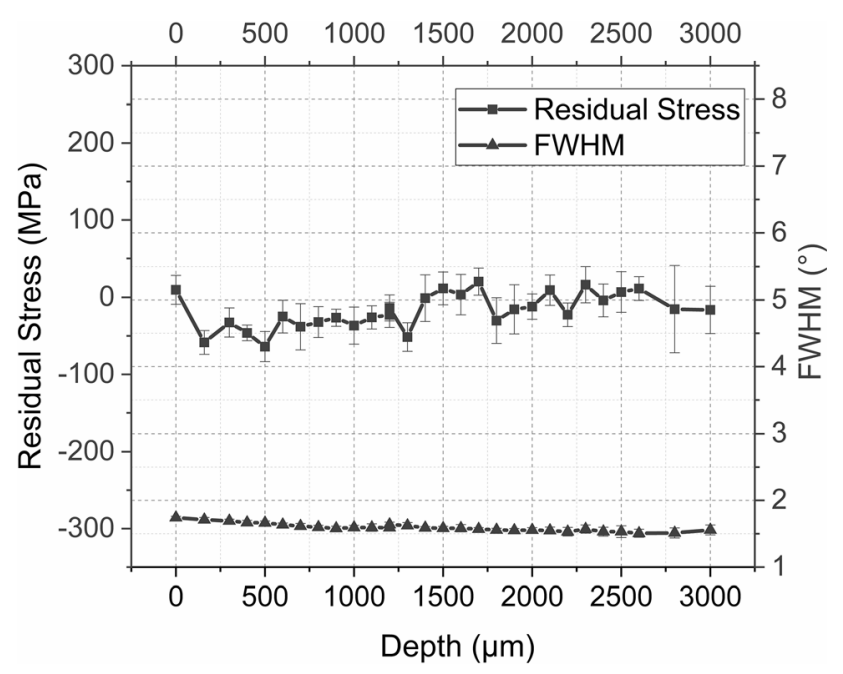

Fig. 11. Residual stress and FWHM data of 14-h gas carburized air-cooled sample

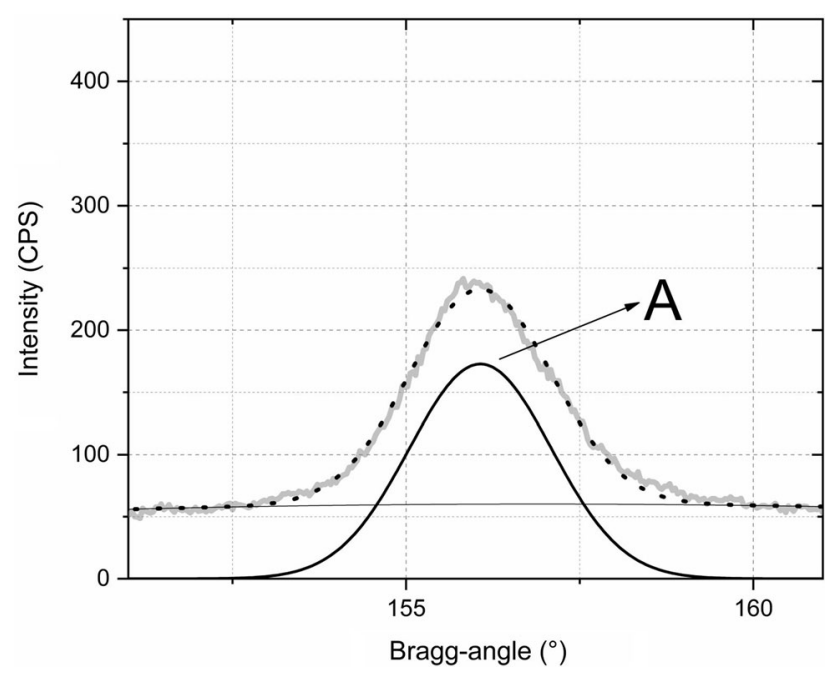

Fig. 12. An example for the imperfect fitting solution of the ferrite (211) interferential function of the quenched sample. The solid gray line is the measured curve. One curve (A) is used for fitting. The dashed line is the composite function of $\mathrm{A}+$ background and does not fit the measured solid gray curve well

curves (maximum intensity and FWHM) were also determined. In the case of hardened samples, the FWHM data of the curves obtained by deconvolution are also different, but this is not due to the crystalline size but mainly due to the dissolved carbon content. At a given depth, the curve with the higher FWHM value represents the martensite phase, and the smaller one corresponds to ferrite in the perlite and the bainite. The FWHM of ferrite in the perlite typically does not change, while the FWHM of martensite may decrease as a function of depth due to lower carbon content.

The volume fraction of phases is proportional to the integrated area of their interference function. The integral area can be calculated as the product of the maximum intensity and the FWHM based on the trapezoidal method. After deconvo- 


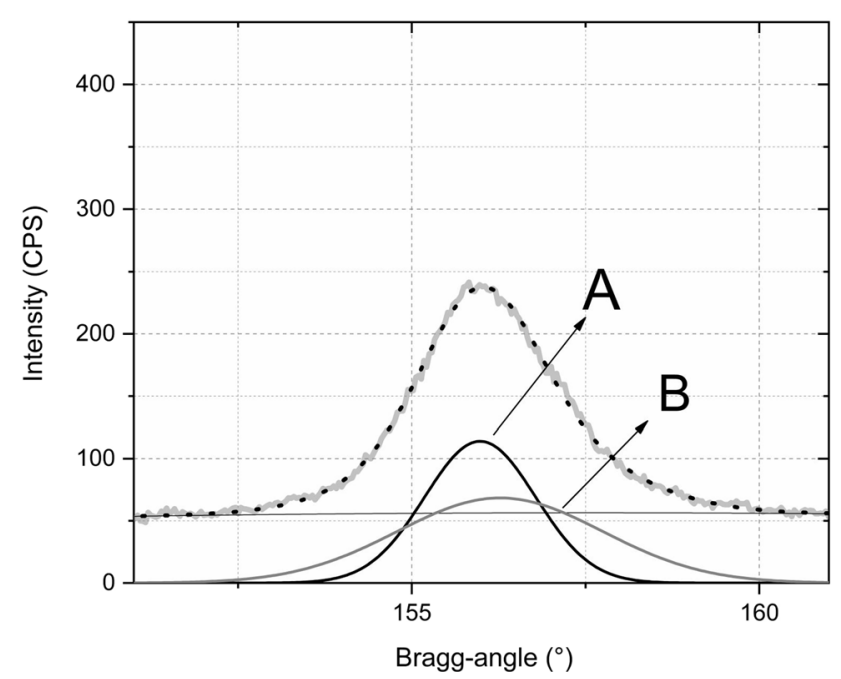

Fig. 13. An example for the perfect fitting solution of the ferrite (211) interferential function of the quenched sample. The solid gray line is the measured curve. Two curves $(\mathrm{A}+\mathrm{B})$ are used for fitting. The dashed line is the composite function of $\mathrm{A}+\mathrm{B}+$ background and fits the measured solid gray curve well

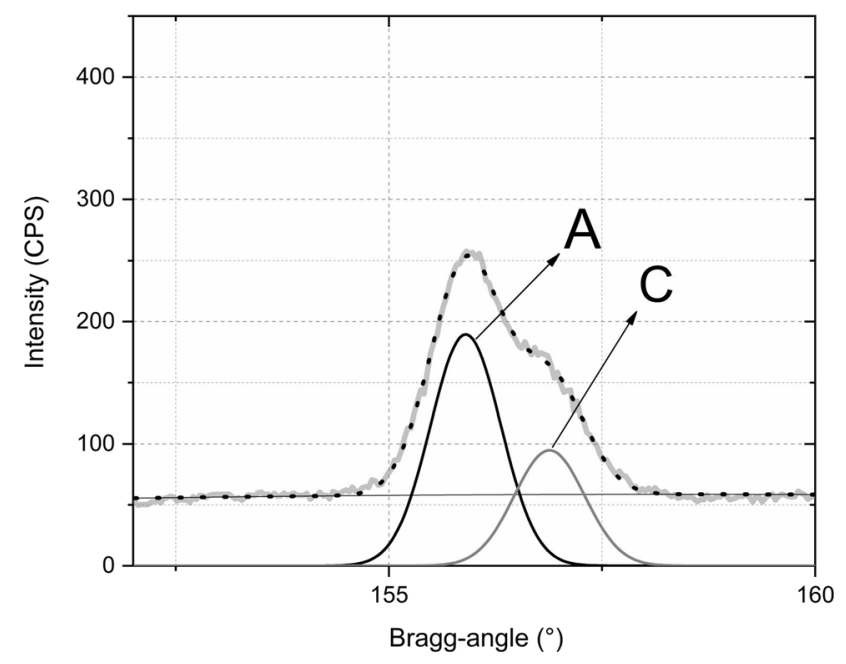

Fig. 14. Fitting procedure in $500 \mu \mathrm{m}$ depth of the air-cooled (fully perlite) pack carburized sample of the ferrite (211) interferential function. The solid gray line is the measured curve. Two curves (A $+C)$ are used for fitting. $\mathrm{C}$ curve is the $\mathrm{K} \alpha_{2}$ peak of $\mathrm{A}$. The dashed line is the composite function of $\mathrm{A}+\mathrm{C}+$ background and fits the measured solid gray curve well

lution, the ratio of the peak with the largest FWHM data, i.e., the martensite microstructural element, was calculated and plotted as a function of depth (Fig. 17) in the quenched samples. There is a decarburized layer in the region of about $200 \mu \mathrm{m}$ from the surface, appearing in the residual stress data. It is clear that the amount of martensite continuously decreases toward the depth in the gas carburized sample. It did not reach $100 \%$ even at its largest amount, at a depth of about 250-500 $\mu \mathrm{m}$. In the pack carburized sample, the amount of martensite starts to decrease from a depth of $1500 \mu \mathrm{m}$, and other microstructural elements appear in the previously purely martensitic structure, as shown by light microscopic images (Fig. 5).

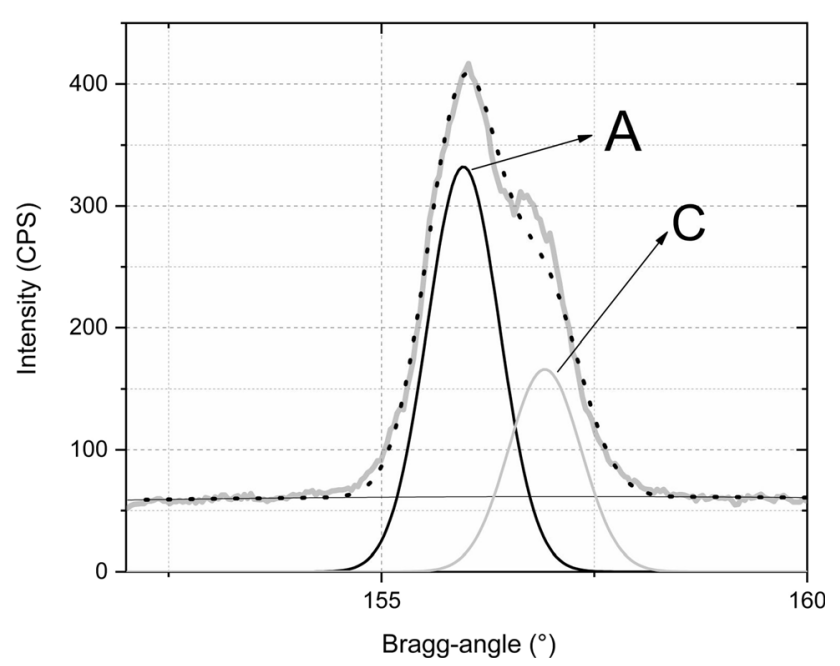

Fig. 15. Fitting procedure in $2000 \mu \mathrm{m}$ depth of the air-cooled (ferrite + perlite) pack carburized sample of the ferrite (211) interferential function. The solid gray line is the measured curve. Two curves $(A+C)$ are used for fitting. $C$ curve is the $K \alpha_{2}$ peak of A. The dashed line is the composite function of $\mathrm{A}+\mathrm{C}+$ background and does not fit the measured solid gray curve

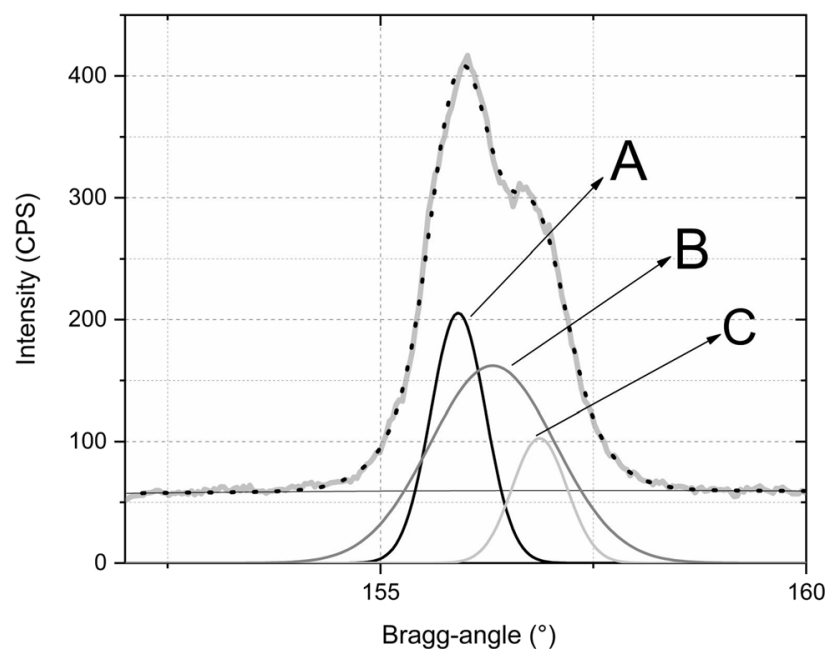

Fig. 16. Fitting procedure in $2000 \mu \mathrm{m}$ depth of the air-cooled (ferrite + perlite) pack carburized sample of the ferrite (211) interferential function. The solid gray line is the measured curve. Three curves $(\mathrm{A}+\mathrm{B}+\mathrm{C})$ are used for fitting. A and B curves represent different ferrite phases with different grain size in ferrite and perlite. $\mathrm{C}$ curve is the $\mathrm{K} \alpha_{2}$ peak of $\mathrm{A}$. The dashed line is the composite function of $\mathrm{A}+\mathrm{C}+$ background and fits the measured solid gray curve well

\section{Discussion}

The significant variation in hardness data is consistent with the variation in carbon concentration during carburization and the resulting formation of heterogeneous microstructural features. The decreasing nature of the macrohardness data is consistent with the variation in the amount of martensite determined by XRD or image analysis. There is no direct correlation between hardness and martensite volume fraction because not only one but several types of microstructural features are formed besides the martensite, and their quantity 

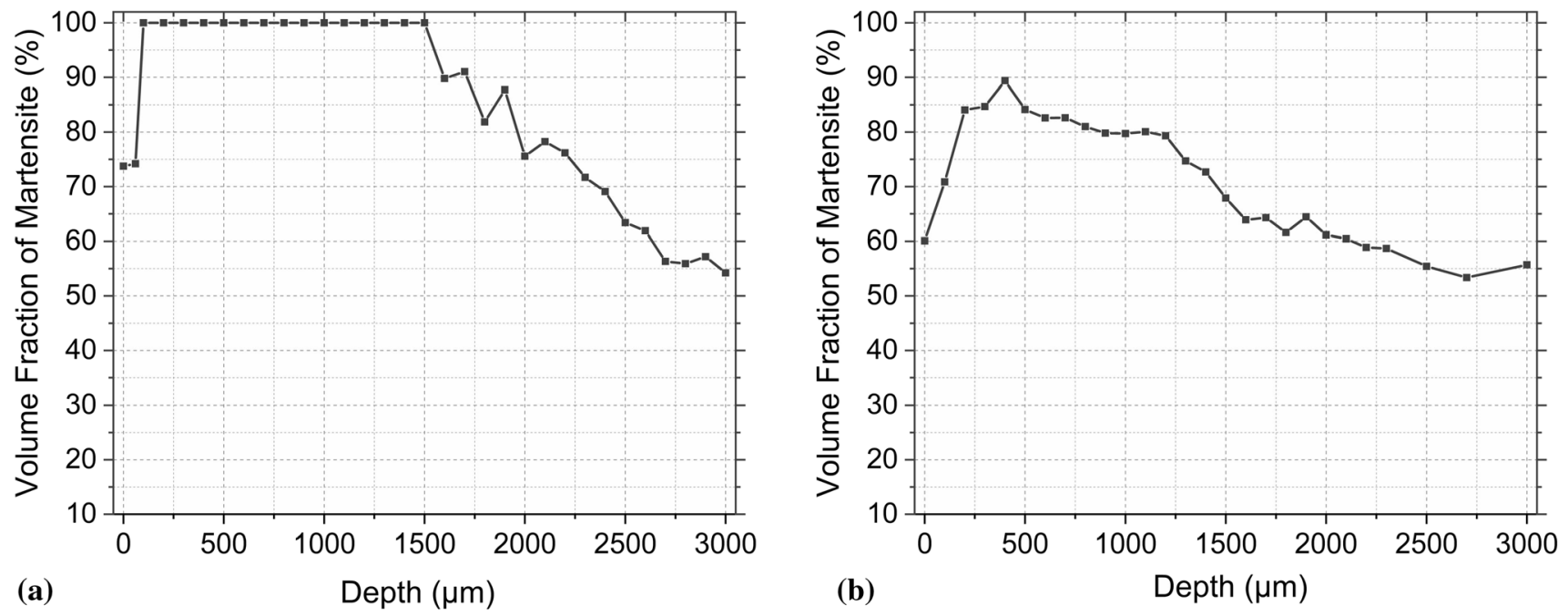

Fig. 17. The volume fraction of the martensite phase in depth is determined by peak deconvolution. (a) 20-hour pack carburized sample; (b) 14-hour gas carburized sample

varies. From the point of view of the application, the residual stress provides complex information. In the pack carburized specimen, the residual stress changes sign, from $+300 \mathrm{MPa}$ tensile stress to $-300 \mathrm{MPa}$ compressive stress in the $1000-\mu \mathrm{m}$ layer, while the macrohardness remains practically unchanged (800 HV1). The decrease in hardness coincides with the transition in residual stress from compressive to the tendency of tensile stress for both samples. It is well correlated with the results after shot peening ( $\operatorname{Ref} 21,36)$. This point occurs at a depth of about $900-1100 \mu \mathrm{m}$ for the pack carburized specimen and $300 \mu \mathrm{m}$ near the surface for the gas carburized specimen. The transition of the residual stress data to compressive stress and then to tensile stress results in an increase and a decrease in the FWHM data, respectively. The excellent correlation of the FWHM data with the microstructure is the most important result. The thickness of the fully martensitic microstructure (case depth) can be determined most accurately from the FWHM data for the 20-hour pack carburized sample. A clear maximum is indicated on the curve. The maximum is also smaller (but definite) for the gas carburized sample, which is explained by the presence of a mixed martensitic-bainitic microstructure. It can be concluded that the FWHM data indicate microstructural changes as reliably as the hardness data. In addition to martensite, the appearance of other structures such as bainite, perlite, or ferrite can be detected with the greatest certainty by peak deconvolution analysis. The (211) interference function of the ferrite phase cannot be fitted by only one peak in some cases. The need for additional peaks during the fitting is possible for two reasons. One is that the reflections of $\mathrm{K} \alpha_{1}, \mathrm{~K} \alpha_{2}$ are separated; this is a standard characteristic of diffraction. Another reason is that the ferrite phase is present in different microstructures with different compositions or grain sizes. For the first, ferrite and martensite, and for the second, the combined presence of ferrite and perlite are a good example. This means that in Fig. 16, curve B is added to describe separate ferrite, which should have a bigger grain size than the ferrite in pearlite, represented by curve A. Here, curve B appears to have a higher FWHM value that does not correlate with the expected larger grain size. But the fact the reflection of the ferrite with smaller grain size (in perlite) is split into $K \alpha_{1}$ and $K \alpha_{2}$ peaks, $A$ and $C$, respectively, must be considered. Thus, the FWHM value of curve $\mathrm{B}$ should be compared to the FWHM value of the composite curves $(\mathrm{A}+\mathrm{C})$. The advantage of the new method is that it is susceptible to these processes. Hence, it is very suitable for detecting other microstructural elements in addition to martensite, which is a significant problem for the carburization process. The detection of other microstructural elements in addition to martensite is of practical importance for carburization. In this case, the martensite and other microstructural features appear at peak deconvolution and can be denoted by peaks with a higher FWHM value and a lower FWHM value, respectively. The curve with a higher FWHM value represents the martensite with distorted lattice. From the signal-deconvolution data, the ratio of the different peaks shows the volume fraction change of different microstructures. This was also confirmed by the metallography images and quantitative analysis. That is, microstructure changes can be well inferred from the signaldeconvolution data.

It can be observed that the residual stress curve in the cemented layer is minimal, i.e., the maximum compressive stress is below the surface, and tensile stress is developed near the surface and in the deeper layers. In the vicinity of the compressive stress maximum (900-1500), the scatter of the results and the uncertainty of the measurement are significant, which is associated with an increase in the FWHM value.

This effect also reflects the presence of different scattering centers with low-volume fractions adjacent to the martensite. In the present case, the diffraction signal consists of a mixed signal of the ferrite phase from martensite to bainite to perlite, with a poor signal-to-noise ratio. The FWHM values are further enhanced because the volume fraction of new scattering centers adjacent to martensite is typically small. The image analysis suggests that they are less than $10 \%$ in total.

The disadvantage of centerless diffractometers is in this case the angular range detected is small compared to detected FWHM values and same with the signal/noise ratio. This problem can be improved by developing detectors. 
Overall, it can be concluded that the variation of the residual stress signal is sensitive to the changes in the carburized layer due to the carbon gradient. The appearance of microstructural features other than martensite, as long as their total volume fraction is small, causes the increase of FWHM value despite the decrease in carbon content. When the amount of microstructural features exceeds about 10\%, the FWHM starts to decrease and fitting the interference function with two or more curves is possible only.

\section{Conclusion}

The most important conclusion from this work was that evaluation of the interference function during residual stress measurement could be used as a non-destructively characterization of the microstructure of the carburized layer. Conventional methods such as hardness testing and optical microscopy cannot detect these changes with such sensitivity.

- The increasing FWHM data indicate the appearance of microstructural elements other than martensite, such as ferrite, perlite, and bainite.

- Signal deconvolution can be used to visibly detect changes in microstructure elements (for example, the martensite ratio).

This promising preliminary work on two samples should be repeated in several other case studies. If validated, this nondestructive method could be used in future cases to provide information on (1) case depth, (2) case hardness, and (3) case microstructure, in addition to the residual stress state of the carburized components. This procedure would be particularly advantageous for quality control. It is non-destructive and could even be carried out with in situ testing integrated into the production line. The non-destructive nature is realized because the depth residual stress measurement can be performed at a part of the component that is not involved in the load or where the tested volume is machined anyway during subsequent processing.

\section{Acknowledgments}

The research work described in the article is supported by the ÚNKP-21-2 new national excelence program of the ministry for innovation and technology from the source of the national research, development and innovation fund. The development of the research method was prepared with the professional support of the doctoral student scholarship program of the co-operative doctoral program of the ministry of innovation and technology financed from the national research, development, and innovation fund.

\section{Funding}

Open access funding provided by University of Miskolc.

\section{Open Access}

This article is licensed under a Creative Commons Attribution 4.0 International License, which permits use, sharing, adaptation, distribution and reproduction in any medium or format, as long as you give appropriate credit to the original author(s) and the source, provide a link to the Creative Commons licence, and indicate if changes were made. The images or other third party material in this article are included in the article's Creative Commons licence, unless indicated otherwise in a credit line to the material. If material is not included in the article's Creative Commons licence and your intended use is not permitted by statutory regulation or exceeds the permitted use, you will need to obtain permission directly from the copyright holder. To view a copy of this licence, visit http://creativecommons.org/licenses/by/4.0/.

\section{References}

1. W.F. Hosford, Iron and Steel, Cambridge University Press, Cambridge, 2012

2. T. Réti, Residual Stresses in Carburized Carbonitrided and Casehardened Components, Handbook of Residual Stress and Steel, ASM International, Ohio, 2002

3. W. Wang, H. Liu, C. Zhu, X. Du and J. Tang, Effect of the Residual Stress on Contact Fatigue of a Wind Turbine Carburized Gear with Multiaxial Fatigue Criteria, Int. J. Mech. Sci., 2019, 151, p 263-273.

4. J. Wu, H. Liu, P. Wei, C. Zhu and Q. Lin, Effect of Shot Peening Coverage on Hardness, Residual Stress and Surface Morphology of Carburized Rollers, Surf. Coat. Technol., 2020, 384, p 125273.

5. K. Sugimoto, T. Hojo and Y. Mizuno, Effects of Vacuum-Carburizing Conditions on Surface-Hardened Layer Properties of TransformationInduced Plasticity-Aided Martensitic Steel, Metals, 2017, 7(8), p 301.

6. P. Hiremath, S. Sharma, M.C. Gowrishankar, M. Shettar and B.M. Gurumurthy, Effect of Post Carburizing Treatments on Residual Stress Distribution in Plain Carbon and Alloy Steels - a Numerical Analysis, J. Mater. Res. Technol., 2020, 9(4), p 8439-8450.

7. Z. Li, A.M. Freborg, B.D. Hansen and T.S. Srivatsan, Modeling the Effect of Carburization and Quenching on the Development of Residual Stresses and Bending Fatigue Resistance of Steel Gears, $J$. Mater. Eng. Perform, 2013, 22(3), p 664-672.

8. E.C.H.C. O'Brien and H.K. Yeddu, Multi-Length Scale Modeling of Carburization, Martensitic Microstructure Evolution and Fatigue Properties of Steel Gears, J. Mater. Sci. Technol., 2020, 49, p 157-165.

9. B. Jo, Y. Shim, S. Sharifimehr and A. Fatemi, Deformation and Fatigue Behaviors of Carburized Automotive Gear Steel and Predictions, Frattura ed Integrità Strutturale, 2016, 10(37), p 28-37.

10. A. Freborg, B. Ferguson, and Z. Li, Predicting Distortion and Residual Stress in a Vacuum Carburized and Gas Quenched Steel Coupon, 2012, p 12

11. U. Tewary, G. Mohapatra and S.S. Sahay, Distortion Mechanisms During Carburizing and Quenching in a Transmission Shaft, J. Mater. Eng. Perform, 2017, 26(10), p 4890-4901.

12. T. Shoji, Z. Lu and Q. Peng, Factors Affecting Stress Corrosion Cracking (SCC) and Fundamental Mechanistic Understanding of Stainless Steels Stress Corrosion Cracking, Elsevier, 2011. https://doi. org $/ 10.1533 / 9780857093769.3 .245$

13. Metals Technical Executive Steering Committee, "Methods of Measuring Case Depth," SAE International, n.d., Doi: https://doi.org/10. 4271/J423_199802

14. K.V. Gogolinskii, V.A. Syasko, A.S. Umanskii, A.A. Nikazov and T.I. Bobkova, Mechanical Properties Measurements with Portable Hardness Testers: Advantages Limitations Prospects, J. Phys. Conf. Ser., 2019, 1384(1), p 012012.

15. L.F.M. Rodrigues, F.C. Cruz, M.A. Oliveira, E.F. Simas Filho, M.C.S. Albuquerque, I.C. Silva and C.T.T. Farias, Carburization Level Identification in Industrial HP Pipes Using Ultrasonic Evaluation and Machine Learning, Ultrasonics, 2019, 94, p 145-151.

16. D. Mercier, J. Lesage, X. Decoopman and D. Chicot, Eddy Currents and Hardness Testing for Evaluation of Steel Decarburizing, $N D T \& E$ Int., 2006, 39(8), p 652-660.

17. M. Sheikh Amiri and M. Kashefi, Investigation of Variables Affecting Impedance Plane in Eddy Current Testing of Carburized Steels, J. Mater. Eng. Perform., 2011, 20(3), p 476-480. 
18. E. Mueller, "Precision of the Residual Stress Determined by x-ray Diffraction: Summery and Limits," 19th International Congress of Metrology (CIM2019), S. Gazal, Ed., (Paris, France), EDP Sciences, 2019, 27001, Doi: https://doi.org/10.1051/metrology/201927001

19. V. Dive and S. Lakade, Recent Research Progress on Residual Stress Measurement Using Non-Destructive Testing, Materials Today: Proceedings, 2021, p S2214785321049464

20. D.T. Whitley, Practical Application of Residual Stress Measurements On Maritime Vessels, n.d., p 100

21. R. Filip, K. Ochał, K. Gancarczyk, W.J. Nowak, B. Kościelniak and B. Wierzba, Characteristics of Impulse Carburization LPC Process, Materials, 2021, 14(15), p 4269.

22. C.J. Ortiz-Echeverri, A. Sanchez-Moguel, I. Rojas-Rodríguez, R. Velazquez-Hernandez, A. Lara-Guevara, and M.E. Rodríguez-García, Non-Contact Characterization of Carbon Content in Steels Using Photocarrier Radiometry, n.d., p 6

23. A. Lara-Guevara, C.J. Ortiz-Echeverri, I. Rojas-Rodriguez, J.C. Mosquera-Mosquera, H. Ariza-Calderón, I. Ayala-Garcia and M.E. Rodriguez-García, Microstructural, Structural, and Thermal Characterization of Annealed Carbon Steels, Int. J. Thermophys., 2016, 37(10), p 99.

24. C. Garcia-Mateo, F.G. Caballero, M.K. Miller and J.A. Jimenez, On Measurement of Carbon Content in Retained Austenite in a Nanostructured Bainitic Steel, J. Mater. Sci., 2012, 47(2), p 1004-1010.

25. Q. Luo, A New XRD Method to Quantify Plate and Lath Martensites of Hardened Medium-Carbon Steel, J. Mater. Eng. Perform., 2016, 25(6), p 2170-2179.

26. M. Sepsi, M. Salata, D. Cseh, V. Mertinger and M. Benke, Significance of the Residual Stress Monitoring in the Automotive Industry, Vehicle and Automotive Engineering. K. Jármai, B. Bolló Ed., Springer International Publishing, Cham, 2018. https://doi.org/10.1007/978-3319-75677-6_24

27. M. Sepsi, D. Cseh, Á. Filep, M. Benke and V. Mertinger, Innovation Methods for Residual Stress Determination for the Automotive Industry, Vehicle and Automotive Engineering. K. Jármai, B. Bollo
Ed., Springer International Publishing, Cham, 2017. https://doi.org/10. 1007/978-3-319-51189-4_41

28. P. Szobota, M. Sepsi and V. Mertinger, Non-Destructive Test for Control of the Surface Quality of Semi Product at the Automotive Industry, Vehicle and Automotive Engineering. K. Jármai, K. Voith Ed., Springer, Singapore, 2021, p 112-122. https://doi.org/10.1007/978-98 1-15-9529-5 10

29. L. Suominen, M. Khurshid and J. Parantainen, Residual Stresses in Welded Components Following Post-Weld Treatment Methods, Procedia Eng., 2013, 66, p 181-191.

30. P. Fu, R. Chu, Z. Xu, G. Ding and C. Jiang, Relation of Hardness with FWHM and Residual Stress of GCr15 Steel after Shot Peening, Appl. Surf. Sci., 2018, 431, p 165-169.

31. J. Li, T. Chaise, D. Nélias, S. Taheri, V. Robin, Ph. Gilles, and G. Douchet, "A Numerical Model to Predict Residual Stresses Induced by Ultrasonic Shot Peening Treatment of Inconel 600,” (Malta), 2011, p 75-84, Doi:https://doi.org/10.2495/SECM110071

32. J. Kelleher, M.B. Prime, D. Buttle, P.M. Mummery, P.J. Webster, J. Shackleton and P.J. Withers, The Measurement of Residual Stress in Railway Rails by Diffraction and Other Methods *, J. Neutron Res., 2003, 11(4), p 187-193.

33. A.R.P. de Dias, R.M. Nunes, T.R.S. de Lima and T.G.R. Clarke, Evaluation of the Residual Stress State of $42 \mathrm{crmo} 4$ Steel Sheets in a Production Line, Mat. Res., 2016, 19(1), p 153-157.

34. P. Paufler and R.A. Young, The Rietveld Method, Cryst. Res. Technol., 1998, 30(4), p 111-185.

35. C. Póliska, Z. Gácsi and P. Barkóczy, The Effect of Melt Flow on the Dendrite Morphology, MSF, 2006, 508, p 169-174.

36. A.D. Krawitz, Introduction to Diffraction in Materials, Science, and Engineering, John Wiley, New York, 2001, p 300-301

Publisher's Note Springer Nature remains neutral with regard to jurisdictional claims in published maps and institutional affiliations. 